\title{
rGO/GO Nanosheets in Tribology: From the State of the Art to the Future Prospective
}

\author{
Maria Sarno ${ }^{1,2, *} \mathbb{C}$, Davide Scarpa ${ }^{3}$, Adolfo Senatore ${ }^{2,3}$ AD $^{\circ}$ and \\ Waleed Ahmed Abdalglil Mustafa ${ }^{3}$ \\ 1 Department of Physics “E.R. Caianiello”, University of Salerno, Via Giovanni Paolo II, 132, \\ 84084 Fisciano, Italy \\ 2 NANO_MATES, Research Centre for Nanomaterials and Nanotechnology at the University of Salerno, \\ University of Salerno, Via Giovanni Paolo II, 132, 84084 Fisciano, Italy; a.senatore@unisa.it \\ 3 Department of Industrial Engineering, University of Salerno, Via Giovanni Paolo II, 132, 84084 Fisciano, Italy; \\ dscarpa@unisa.it (D.S.); wahmedabdalglilmustafa@unisa.it (W.A.A.M.) \\ * Correspondence: msarno@unisa.it; Tel.: +39-089963460
}

Received: 22 January 2020; Accepted: 4 March 2020; Published: 10 March 2020

check for updates

\begin{abstract}
In the last few decades, in the lubricant industry, the request for new performing additives has been becoming imperative. In this scenario, control at the nanoscale can be the key factor for the improvement of more efficient nanolubricants. Herein, after a discussion about the nanoparticles' four main lubrication mechanisms, considerable attention is devoted to the usage of reduced graphene oxide/graphene oxide (rGO/GO) nanosheets in tribology. Moreover, graphene surface functionalization is reviewed, also including unexplored results in the field of lubrication. As far as the literature is concerned, it can be postulated that $\mathrm{rGO} / \mathrm{GO}$ nanosheets can reduce wear and friction. Wear reduction is obtained by deposition and film formation, while friction reduction is related more to the shear and lamination of the sheets on the contacting surfaces. Nevertheless, the two phenomena are interrelated and work in sync. In this context, it is of high importance to form a homogenous suspension for a continuous nanosheet supply after deposition and shearing. The focus of this review was placed on the main issues still to be overcome, e.g., the literature results in rationalization; dispersion stability enhancement; and finding the optimum concentration in the delicate balance of different components. Possible solutions for their efficient overcoming are eventually reported.
\end{abstract}

Keywords: reduced graphene oxide/graphene oxide; wear reduction; friction reduction; homogenous suspension; optimum concentration

\section{Introduction}

Nowadays, there is a growing demand for highly efficient lubricants. Several aspects define a lubricant's efficiency, including the energy consumption reduction percentage, an increase of machines' service life, eco-friendliness and long-time performance. Conventional lubrication depends on the choice of different types of liquid lubricants as intermediate means between metal surfaces in contact. The major constituents of a fully formulated lubricant are hydrocarbon molecules, whereas the remaining part is made up of performing additives. These additives include friction and wear modifiers, which for many years have been represented by organic carboxylic acids and phosphorus-based chemicals [1-3].

Lubrication is a complicated phenomenon, and it is most convenient to consider it as a system which is a function of many factors such as the lubricated surface characteristics, chemical and physical interactions between lubricant molecules and rubbing conditions, thin film dynamics in steady and transient conditions. 
In order to improve the effectiveness of such a complex system, nanoparticles can be chosen as lubrication additives, which, even in small amounts, can bring about substantial improvements in physical properties, i.e., thermal, heat dissipation [4,5], as well as work as friction modifiers (FM) and anti-wear agents (AW) [6-9]. This positive attribute is due to their chemical stability, limited interaction with other additives and non-volatility, resulting in excellent durability in harsh conditions [10]. The latter advantage of nanoparticles is a big drawback for organic traditional FM and AW additives. Therefore, researchers began to study nanoparticles for the reduction and optimization of friction and wear.

A mixture of nanoparticles and base oil is known as a nano-lubricant, which is a specific class of nanofluids. In general, nanofluids can be formulated through either a two-step or a one-step method. The two-steps technique consists of first synthesizing the nanoparticles and subsequently dispersing them in the fluid. The dispersion step is carried out by diffusing high kinetic energy through the mixture, which can be done either by ultra-sonication, ball milling or stirred homogenization. In the alternative one-step method, both the steps are simultaneously conducted. The formation of nanoparticles occurs directly within the fluid-utilizing techniques such as chemical vapor deposition (CVD) and condensation on the oil bulk phase. However, the latter method is still expensive and far from occurring at large production rates, regardless of its capability to form nanoparticles with a higher quality.

In this review, the focus has been placed on graphene's $(G)$ main derivatives, graphene oxide (GO) and reduced graphene oxide (rGO), as lubricant additives for friction and wear reduction. The reason for focusing on rGO and GO includes the possibility of their mass production with respect to pristine G [11]. There are several differences and contrasts between rGO and GO. The former one has more effective dispersion abilities in non-polar solvents in comparison to GO [12] and possesses relatively restored superior mechanical and thermal conductivity properties after reduction [13], while the abundant presence of reactive oxygen groups on the GO's surface favors its functionalization for an enhanced dispersion [14]. Regardless of all these differences, both rGO and GO have friction- and wear-reduction properties when added to a lubricant oil.

$\mathrm{G}$ is one of the strongest materials [15] in the form of a monolayer. Moreover, G's multi-layers are easily sheared [16], due to both the weak van der Waals forces between its sheets [17] and its high chemical stability [18]. These characteristics make it an excellent candidate as a lubricant additive, mainly for friction and wear reduction. In particular, the two-dimensional graphene sheets gained considerable attention as a solid lubricant. Nevertheless, the usage of $\mathrm{G}$ and its derivatives as additives in liquid lubricants still requires more comprehensive analyses.

In order to maximize the tribological merits of nanoparticles' utilization as additives in lubricant oils, apart for nanomaterials' size (indeed, the hardness of nanoparticles increases as the particle size increases [19], and when this hardness becomes higher than the one of the tribo-pair scratching and/or indentation can occur), two factors play a significant role: the nanoparticles' concentration optimization [20] and the requirement of a stable and homogenous dispersion [20,21]. In particular, the concentration optimization is still far from being standardized and rationalized, since it strongly depends on the characteristics of the base oil, the additive and their mixture. On the other hand, the achievement of a stable nanoparticle dispersion, the object of few literature studies which is often neglected, still represents an actual obstacle for a sustainable application [22].

In the particular case of $\mathrm{G}$ and its derivatives, the aforementioned instability is caused by different factors. First, $G$ and its derivatives exhibit a very large surface area of $\sim 2590 \mathrm{~m}^{2} \mathrm{~g}^{-1}$ [23], which gives rise to a high interface area and high surface energy within the solvent, pushing the sheets to aggregate in order to reduce this huge energy. Additionally, the sheets tend to re-stack and re-aggregate under van der Waals interactions [24]. In the case of non-polar solvents, which constitute the majority of lubricant mediums, the difficulty in forming a stable $\mathrm{G}$ suspension is even greater, due to their inert nature.

In summary, this review, after introducing the four main lubrication mechanisms of nanoparticles, such as tribofilm formation due to tribochemical reaction [25,26], ball bearing [27,28], mending and 
the polishing effect [29,30], focuses considerable attention on the adoption of rGO/GO in the field of tribology and includes a critical review dedicated to the optimization of nanoparticles, as well as to nanoadditives' functionalization to give a stable and homogenous suspension. An overview of this study is presented in Figure 1.

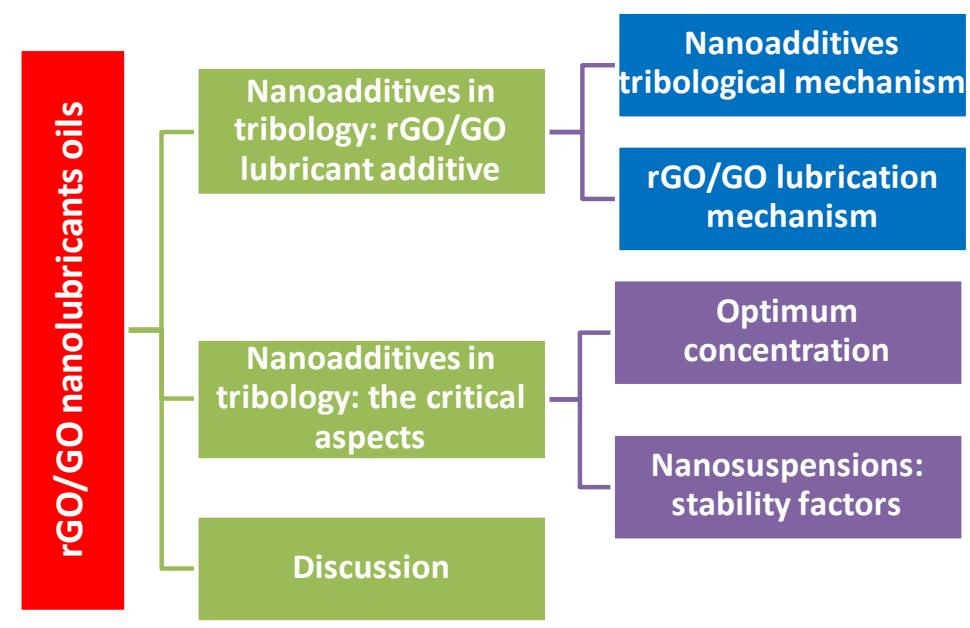

Figure 1. The review structure. rGO stands for reduced graphene oxide and GO for graphene oxide.

\section{Nanoadditives in Tribology: rGO/GO Lubricant Additive}

\subsection{Nanoadditives Tribological Mechanism}

In nanoadditive-containing oils, nanoparticles work through different tribological mechanisms. Although the specific nanoadditives' role is still not fully clarified since the analysis of the rubbed surfaces or in situ microscopy during tests are required for a full understanding, experimental studies concluded that the mechanism depends on the nature of the particles, i.e., their structure, morphology, size, etc., and on test conditions [31].

The role of nanoparticles can be classified into two main categories [32]. The first is the direct role, which includes the ball bearings effect and protective/tribofilm formation. The secondary effect participates in surface protection via the mending/repairing effect and polishing/smoothing effect. Additionally, the relatively high thermal conductivity of nanoparticles, deposited between the tribopairs, can help the dispersion of the friction-generated heat, reducing the thermal stress on the asperities.

\subsubsection{Ball Bearings Effect}

This role is played by the spherical or semi-spherical nanoparticles. Due to their intrinsic morphological properties, these nanoparticles can convert sliding friction between the mating surfaces into rolling friction, which results in a reduction of the friction coefficient [33]. The research about nanolubricants with such a shape is still ongoing. Recently, it has been suggested that these nanoparticles could either roll or be embedded in the surface [34]. In particular, this study elucidated that nanoparticles' behavior depends on the differences between the hardness of the particles and that of the surfaces, revealing for instance that nanodiamonds are prone to being embedded into softer surfaces and to rolling on harder ones.

\subsubsection{Protective/Tribofilm Formation}

The main hypothesis of this technique is based on the idea of the formation of a thin layer of nanoparticles on the tribo-contact zone. This layer will act as a barrier for the asperities and valleys of the contacting surfaces, reducing the wear rate. An additional feature of this deposited film is the ease of shear, which can be attributed to lower friction between surfaces. The theory of tribo-film 
formation is considered the most dominant mechanism among the nanolubricant methods of operation: it was reported and proven in different studies with various nanoparticles and characterization techniques [35-37]. There are main parameters that affect the process of film formation, including the sufficiently small size of the dispersed nanoparticles which must guarantee easy access to the sliding surfaces [38,39]. Moreover, in the case of high loads conditions, additional tribo-chemical reactions can occur between the sliding surfaces and nanoparticles [40,41].

\subsubsection{Mending/Repairing Effect}

This mechanism is important for the mechanical parts which fall under repetitive stress and may fail due to cracks. Cracks can exceed the tribo contact zone and propagate throughout the metal body. The mechanism works by the filling and/or by the sintering and melting of small nanoparticles into the initiated macrocracks, thus reinforcing the metal surface. This effect was mentioned by several studies as being a result of the tribo-sintering of nanoparticle additives [42-44]. In particular, it regards NPs' deposition on the interacting surfaces, which compensates for the loss of mass. During this phenomenon, NPs deposit on the worn surface by limiting abrasion [45]. Moreover, the addition of high thermal conductivity nanoadditives, such as nanocarbons [46], can determine an increased thermal conductivity [20-26,47], which facilitates heat dissipation and reduces cracks' occurrence.

\subsubsection{The Polishing/Smoothing Effect}

The accumulation of nanoparticles on the surface of the valleys' profile helps smooth the metal surfaces. This effect ultimately reduces friction and allows the lubricant oil to form more continuous and efficient films. This polishing effect was noticed by measuring the surface profile of test specimens before and after tests for pure lubricant oil and oil with nanoadditives, indicating a significant reduction of the surface roughness due to nanoparticles' deposition [48,49].

\section{2. $r G O / G O$ Lubrication Mechanism}

As the main interest of this review is the adoption of rGO and GO nanosheets in tribology, the focus will be on lamellar structures and their behavior under different conditions. The main lubrication mechanism of lamellar nanoparticles, such as graphene and $\mathrm{MoS}_{2}$, derives from the formation of a tribo-film which acts as a protective layer between the metal pairs [50]. Additionally, polishing or smoothing effects are also reported in the literature [51].

Lin et al., 2011, attributed the outstanding lubrication performance of rGO nanoparticles to their small size and extremely thin laminated structure, allowing the rGO sheets to easily access the contact area, thereby preventing the rough surfaces from coming into direct contact [20]. Zhang et al., 2011, explained the rGO tribological mechanism by revealing the formation of a protective layer on the surface of the steel ball specimen at not so high nanoadditive concentrations (i.e., when exceeding a critical value, dry contact occurs), which indicates an enhanced anti-wear performance due to smoothed surfaces with reduced roughness [52]. In the study by Mungse et al., 2014, the excellent performance of $\mathrm{rGO}$, whose dispersion in lube oil was enhanced by a modification obtained through a chemical procedure for selective inclusion of long alkyl chains on the edges and defects sites through amide linkage, as a lubricant additive are the results of: (a) the weak van der Waals interactions between the lamellas of the modified rGO sheets, which make them easy to be sheared under the rolling contact stress; and (b) the continuous supply of the modified rGO sheets on the contact surfaces due to their stable dispersion in the lube oil [53].

Kim et al., 2011, demonstrated the importance of graphene as the thinnest solid lubricant that reduces adhesion and friction forces between the contact surfaces at the nano and microscale while protecting the coated surfaces at once [54]. Additionally, Sarno et al., in 2014, showed that the protection offered to the tribo-interfaces by the laminated structure of reduced GO nanosheets generated during sliding was suitable for reducing friction and wear [9]. 
Berman et al., 2013, found that, after 400 cycles of sliding contact, ethanol-processed graphene was gradually removed from the wear track; consequently, friction increased until a new dose of graphene was supplied to the contact interfaces. Therefore, for an efficient performance, the long-term dispersion stability of graphene nanosheets in lube oil is essential for their uninterrupted supply to the contact interfaces [55].

Mungse et al., 2015, observed that modified GO nanosheets dispersed in lube oil are deposited on the contact interfaces under the sliding tribo-stress, as confirmed by Raman Spectroscopy. It was proposed that under the sheared contact, some of the graphene layers are delaminated and then deposited on the contact interfaces. As the sliding goes on, the dispersed modified GO nanosheets in the lube oils easily sheared with the weakly adhered graphene on the contact interfaces of the steel ball and disc (Figure 2a,b), reducing the friction significantly [56]. Additionally, in the case of $\mathrm{MoS}_{2}$ nanosheets, it has been found that, under the sheared contact, delaminated sheets are weakly deposited on the contact interfaces. It was observed that the deposition and then removal of $\mathrm{MoS}_{2}$ nanosheets from the contact interfaces was a continuous process under the sliding contact stress [57]. Furthermore, deposited graphene nanosheets on contact interfaces protect the surface against the tribo-damages. Hence, for maintaining the low friction and protection of contact surfaces, the uninterrupted supply of solid lubricant additive is very important. This can be obtained by a thorough dispersion of graphene nanosheets in the lube oil [56]. Patel et al., 2019, investigated the tribological effects of highly reduced graphene oxide (H-rGO) nanoplatelets as additives to mineral base oil, aiming to exploit the fewer oxygen groups present between the microlayers, allowing spacing between the surfaces to accommodate the lubricant [58]. Liñeira del Río et al., 2019, [59] studied the tribological properties of nanolubricants formed by trimethylolpropane trioleate (TMPTO) or polyalphaolefin (PAO 40) base oils with reduced graphene oxide sheets (rGO) [60-63] whose reduction was carried out in order to obtain a good stability of the nanoadditives in the fluids, observing $24 \%$ and 20\% friction enhancement for the PAO 40 and the TMPTO base oils, respectively. Mungse et al., 2019, prepared alkylated graphene oxide (GO)/reduced graphene oxide (rGO) by covalent interaction with octadecyltrichlorosilane (OTCS) and octadecyltriethoxysilane (OTES), finding that the variable oxygen functionalities in the $\mathrm{GO} / \mathrm{rGO}$ and hydrolysis rate of octadecylsilanes governed the grafting density of octadecyl chains on the GO and rGO. In terms of the coefficient of friction and wear scar diameter, the tribological properties revealed a good correlation with the structure of alkylated GO/rGO and their dispersion stability in the polyol lube base oil [64].

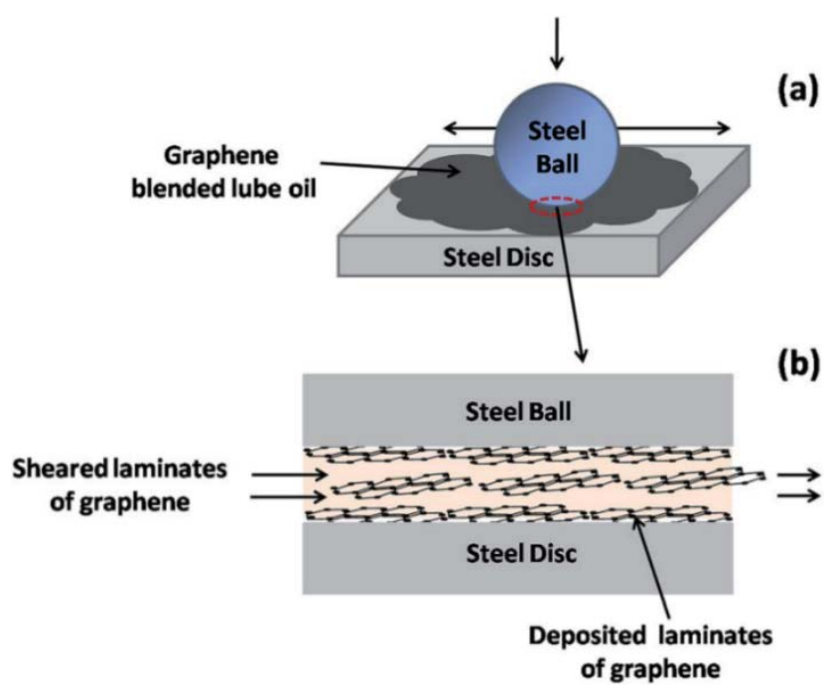

Figure 2. Schematics illustration of the role of graphene nanosheets under the sliding contact [56]. (a) The ball-on-disc contact with GO-octadecylamine (ODA) blended lube oil. (b) The image of the contact interfaces was magnified in order to show the deposited and sheared graphene nanosheets, which are responsible for friction and wear reductions. [RSC Adv., 2015, 5, 25565-25571]-Reproduced by permission of The Royal Society of Chemistry. 


\section{rGO/GO Behavior in Different Lubrication Conditions}

Most of the studies confirmed the beneficial role of rGO/GO nanosheets in different types of base lubricant oils. With regards to the lubricant film thickness, four different regimes can be recognized: hydrodynamic, boundary, mixed and elastohydrodynamic, as shown in Figure 3. Because of the different film thicknesses between tribo-surfaces, nanolubricants were typically explored in two lubrication regimes, characterized by high load and speed: boundary, with a film thickness $\leq 70 \mathrm{~nm}$, and mixed, with a film thickness between $70 \mathrm{~nm}$ and $1 \mu \mathrm{m}$ [65]. Under these intensive conditions, rGO/GO nanosheets play a significant role in the lubrication process. However, one of the most important factors for the nanosheets to be activated within this thin film is their ability to deposit onto the contacting regions and form a continuous film. This formation requires a good dispersion capability and, depending on the binding forces, that speeds do not exceed a critical value to be drifted away with the film flow [66].

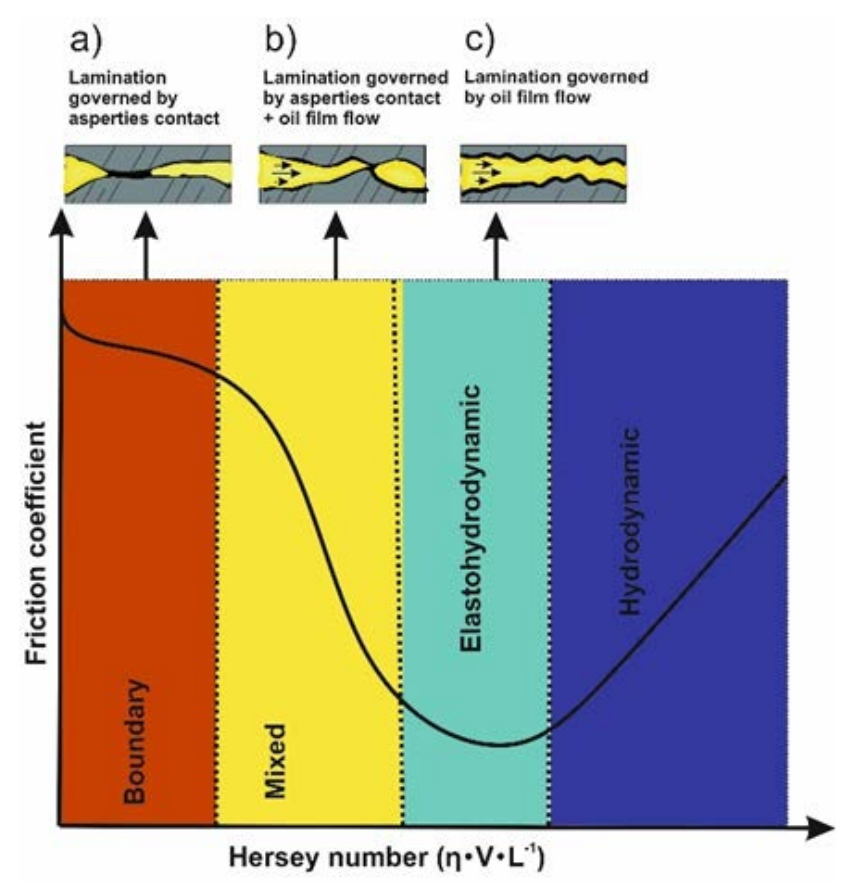

Figure 3. Lubrication in the different lubrication regimes: (a) boundary, (b) mixed, (c) elastohydrodynamic and hydrodynamic. $\eta$, viscosity; $V$, speed; $L$, load.

\section{Nanoadditives in Tribology: The Critical Aspects}

\subsection{Optimum Concentration}

The optimum concentration of additives in lubricating oils is a function of the amount of particles performing their tribological properties and can decrease with an increased dispersion stability. The enhancement of the lubrication performance which occurs when a small amount of graphene is added is related to the formation of a protective layer between the rubbing surfaces. The utilization of the optimum concentration is of great significance as an excess in loading could result in the formation of a discontinuous oil layer [52]. This can deteriorate the anti-wear performance due to the partial dry friction or transition to boundary regions. In Table 1, some of the main results regarding this topic are shown (see column 4). 
Table 1. Overview of the main literature results concerning the use of reduced graphene oxide and graphene oxide (rGO/GO) as lubricant additives, with particular attention on dispersion stability, additive concentrations and related performance.

\begin{tabular}{|c|c|c|c|c|c|c|c|c|c|c|c|}
\hline Ref. & Year & Method of Stabilization & $\begin{array}{c}\text { Optimum } \\
\text { Concentration }\end{array}$ & Lubricant Oil & Stability & Tribometer & Load & Speed & Temperature/Time & $\begin{array}{c}\text { Wear } \\
\text { Reduction }\end{array}$ & $\begin{array}{c}\text { Friction } \\
\text { Reduction }\end{array}$ \\
\hline [67] & 2017 & $\begin{array}{l}\text { Mild thermal reduction of GO } \\
\text { achieved by treatment at } 700^{\circ} \mathrm{C}\end{array}$ & $0.5 \mathrm{wt} \%$ & Base oil PAO 6 & $25 \mathrm{~h}$ & Ball-on-disc & $2 \mathrm{~N}$ & $24 \mathrm{rpm}$ & $\mathrm{NA} / 1.5 \mathrm{~h}$ & $\begin{array}{c}\text { Positive } \\
\text { effect }\end{array}$ & $30 \%$ \\
\hline [68] & 2017 & $\begin{array}{l}\text { Covalent functionalization with } \\
\text { organic moiety * }\end{array}$ & $0.01 \mathrm{wt} \%$ & Base oil (type NA) & 1 month & 4-ball & $400 \mathrm{~N}$ & $1200 \mathrm{rpm}$ & Room/1 h & $30 \%$ & $16 \%$ \\
\hline [56] & 2015 & $\begin{array}{l}\text { Basal plane modification with } \\
\text { octadecylamine * }\end{array}$ & $0.02 \mathrm{mg} \mathrm{mL}^{-1}$ & $\begin{array}{l}\text { Commercial engine } \\
\text { oil } 10 \mathrm{~W}-40\end{array}$ & 1 month & $\begin{array}{l}\text { Standard steel balls } \\
\text { reciprocating } \\
\text { ball-on-disc }\end{array}$ & $100 \mathrm{mN}$ & $\begin{array}{l}\text { Micro: } 1 \mathrm{~cm} \mathrm{~s}^{-1} \text {; } \\
\text { standard: } 3 \mathrm{~cm} \mathrm{~s}^{-1}\end{array}$ & Room $/ 1 \mathrm{~h}$ & $25 \%$ & $25 \%$ \\
\hline [20] & 2011 & $\begin{array}{c}\text { Stearic and oleic acids (mass ratio } \\
\text { 3:5) modification }\end{array}$ & $0.075 \mathrm{wt} \%$ & Base oil SN350 & NA & 4-ball & $147 \mathrm{~N}$ & $1200 \mathrm{rpm}$ & $75 \pm 2{ }^{\circ} \mathrm{C} / 1 \mathrm{~h}$ & $0.8-0.3$ & $0.15-0.12$ \\
\hline [52] & 2011 & Modification with oleic acid & $0.02-0.06 \mathrm{wt} \%$ & Base oil PAO9 & NA & 4-ball & $400 \mathrm{~N}$ & $1450 \mathrm{rpm}$ & Room/NA & $14 \%$ & $17 \%$ \\
\hline [53] & 2014 & $\begin{array}{c}\text { Amide linkage for } \\
\text { octadecylamine defects edges } \\
\text { sites modification * }\end{array}$ & $0.02 \mathrm{mg} \mathrm{mL}^{-1}$ & $\begin{array}{l}\text { commercial engine } \\
\text { oil }(10 \mathrm{~W}-40)\end{array}$ & 1 month & 4-ball & $392 \mathrm{~N}$ & $1200 \mathrm{rpm}$ & $75^{\circ} \mathrm{C} / 1 \mathrm{~h}$ & $26 \%$ & $9 \%$ \\
\hline [69] & 2015 & $\begin{array}{l}\text { Use of a dispersant: poly } \\
\text { isobutylene succinic imide in oil }\end{array}$ & $0.5 \mathrm{wt} \%$ (used) & $\begin{array}{c}\text { API Gr I and II + } \\
\text { linear alkyl benzene }\end{array}$ & 1 year & Block-on-ring & $900 \mathrm{~N}$ & $1125 \mathrm{rpm}$ & $50-110^{\circ} \mathrm{C} / 3 \mathrm{~h}$ & $\begin{array}{c}\text { Positive } \\
\text { effect }\end{array}$ & $0.07-0.02$ \\
\hline [70] & 2018 & Use of a surfactant: oleic acid & $0.4 \mathrm{wt} \%$ & A5 $(5 W-30)$ & NA & $\begin{array}{l}\text { Setup: bench of ring } \\
\text { line (reciprocation) }\end{array}$ & $9-368 \mathrm{~N}$ & $0.154-0.6 \mathrm{~m} / \mathrm{s}$ & Room/NA & $22 \%-29 \%$ & $29 \%-35 \%$ \\
\hline [71] & 2016 & $\begin{array}{l}\text { Graphene balls formation by } \\
\text { using an aerosol capillary } \\
\text { compression approach }\end{array}$ & $0.01-0.1 \mathrm{wt} \%$ & Base oil PAO4 & $20 \mathrm{~h}$ & $\begin{array}{l}\text { Pin-on-disk/boundary } \\
\text { regime }\end{array}$ & $10 \mathrm{~N}$ & $\begin{array}{c}\text { Linear sliding }(10 \\
\mathrm{mm} / \mathrm{s})\end{array}$ & Room $/ 0.5$ or $1 \mathrm{~h}$ & $\sim 85 \%$ & $20 \%$ \\
\hline
\end{tabular}

${ }^{*}$ Covalent immobilization. 
In particular, Zhao et al. [67] report the preparation of mildly thermally reduced graphene oxide at $700{ }^{\circ} \mathrm{C}$ for $5 \mathrm{~h}$, which shows an optimal concentration of $0.5 \mathrm{wt} \%$, beyond which additive aggregation under lubrication conditions highly occurs, leading to a reduced permeation of the as-obtained rGO aggregates into the rubbing surfaces. This agglomeration phenomenon at higher concentrations also occurs with chemically modified rGO [68] and surfactant-stabilized graphene nanosheets [70]: beyond the optimum concentration value, the higher the sheets aggregation (which could be caused by additive instability in oil), the more likely that the uninterrupted supply to metal surfaces could be not provided. In addition, aggregation can also start at the concentration at which lubricating surfaces become saturated with additive nanosheets [70]. In [68], the optimum concentration of the synthesized functionalized reduced graphene in base oil is $0.01 \mathrm{wt} \%$, and the authors clearly explain the reason to choose this optimum amount, since: (1) at lower concentrations (0.005 wt $\%)$, rGO can easily disperse, though, due to the shortage of additive, the additive sheets cannot cover the whole metal surfaces with their protective film; (2) at higher concentration $(0.015 \mathrm{wt} \%)$, the excess sheets will act as debris, producing abrasive-like wear. A similar trend in additive concentration and a similar corresponding explanation can also be formulated for the basal plane octadecylamine functionalized GO [56] and the stearic/oleic acid-modified graphene platelets [20]. The latter also showed a similar trend with regard to the load-carrying capacity. As previously mentioned, Zhang et al. [52] give a more detailed explanation of this phenomenon, which is related to the importance of maintaining the continuity of the oil layer during lubrication. The authors produced oleic acid-modified graphene sheets, observing an optimum concentration of the additive in base oil of $0.02-0.06 \mathrm{wt} \%$. According to them, the optimum corresponds to the amount of graphene sheets on the lubricating surfaces which maximizes the ratio between the oil film thickness and surface roughness, i.e., the maximum shift from a mixed to boundary lubrication regime. At higher concentrations than the optimum one, the graphene sheets pile up between the lubricating surfaces, breaking the continuity of the oil film and determining again a fall into the mixed regime and, eventually, dry contact. More generally, wear and friction decrease with the gradual addition of graphene up to a specific concentration, after which they start to rise, achieving values higher than the ones shown by the free-additives oil (i.e., lubrication governed by solid nanoparticles, "dry lubrication"). In other words, this behavior is explained by the existence of a graphene coating on the surface, which decreases the height of the asperities and hence reduces the roughness, resulting in a thinner oil layer turning the lubrication to a boundary regime. It was assumed that friction was a function of three terms, as illustrated in Equation (1) [52]:

$$
F_{C}=\frac{F C_{o} A_{o}+F C_{g} A_{g}+F C_{f} A_{f}}{A_{o}+A_{g}+A_{f}}
$$

where $A_{0}, A_{g}$ and $A_{f}$ are the friction area between friction pairs separated by oil-containing graphene, friction area separated only by graphene (dry-contact) and dry-contact area of furrows, respectively. The progressive addition of graphene determines an increase of $A_{g}$ and a reduction of $A_{f}$. This is true until a certain point and results in friction and wear reductions. On the other hand, after that point, $A_{g}$ increases, generating an abrasive effect with wear and friction that is higher than for pure oil.

Eventually, it is worth mentioning that the morphology and dimensions of additives can also be crucial in determining the effect of additive concentration on tribological performance. For instance, Dou et al. [71] produced ultrafine particles consisting of crumpled, paper-ball-like graphene which, unlike more traditional GO/rGO nanosheet additives, show no significant variation in the friction coefficient and wear reduction at both $0.01 \mathrm{wt} \%$ and $0.1 \mathrm{wt} \%$ due to their high self-dispersion and aggregation-resistant properties.

\subsection{Nanosuspensions: Stability Factors}

Suspension stability is one of the main factors affecting the tribological performances of lubricant oils. This is a topic not fully explored at all. 
Suspended nanoparticles are pushed to attract each other, driven by their high surface energy. DLVO theory (named after Boris Derjaguin, Lev Landau, Evert Verwey and Theodoor Overbeek, who formulated it) suggests that the stability of a nanofluid suspension is determined by a balance between van der Waals attractive forces among nanoparticles and the electrical double layer repulsive forces [66]. Van der Waals forces are almost always present, and they result from interactions between the either rotating or fluctuating dipoles of atoms and molecules. In the simplest situation, this interaction can be modeled as Equation (2) [72]:

$$
W_{v d W}(h)=\frac{-H}{12 \pi h^{2}}
$$

where $H$ is the Hamaker constant, which defines forces' strength, and $h$ is the surface separation. In most of the situations, the Hamaker constant is positive, meaning that the van der Waals force is attractive. Typical values of $H$ are in the range of $10^{-21}-10^{-19} \mathrm{~J}$. Double layer interactions can be approximated as in Equation (3) [72]:

$$
W_{d l}(h)=\frac{2 \sigma_{+} \sigma_{-}}{\varepsilon_{0} \varepsilon k} e^{-k h},
$$

where $\sigma_{+}$and $\sigma_{-}$are the surface charge densities per unit area of the right and left surfaces, $\varepsilon_{0}$ is the permittivity of vacuum, $\varepsilon$ the dielectric constant of the liquid medium, and $k$ is the inverse Debye length [72].

As shown in Figure 4, in the state of a random Brownian movement of suspended nanoparticles, the stability is governed by repulsive forces greater than attractive interactions. Electrostatic repulsions between nanoparticles, as well as steric repulsions, (Figure 4a) can generate a stable homogenous suspension (Figure $4 b$ ).

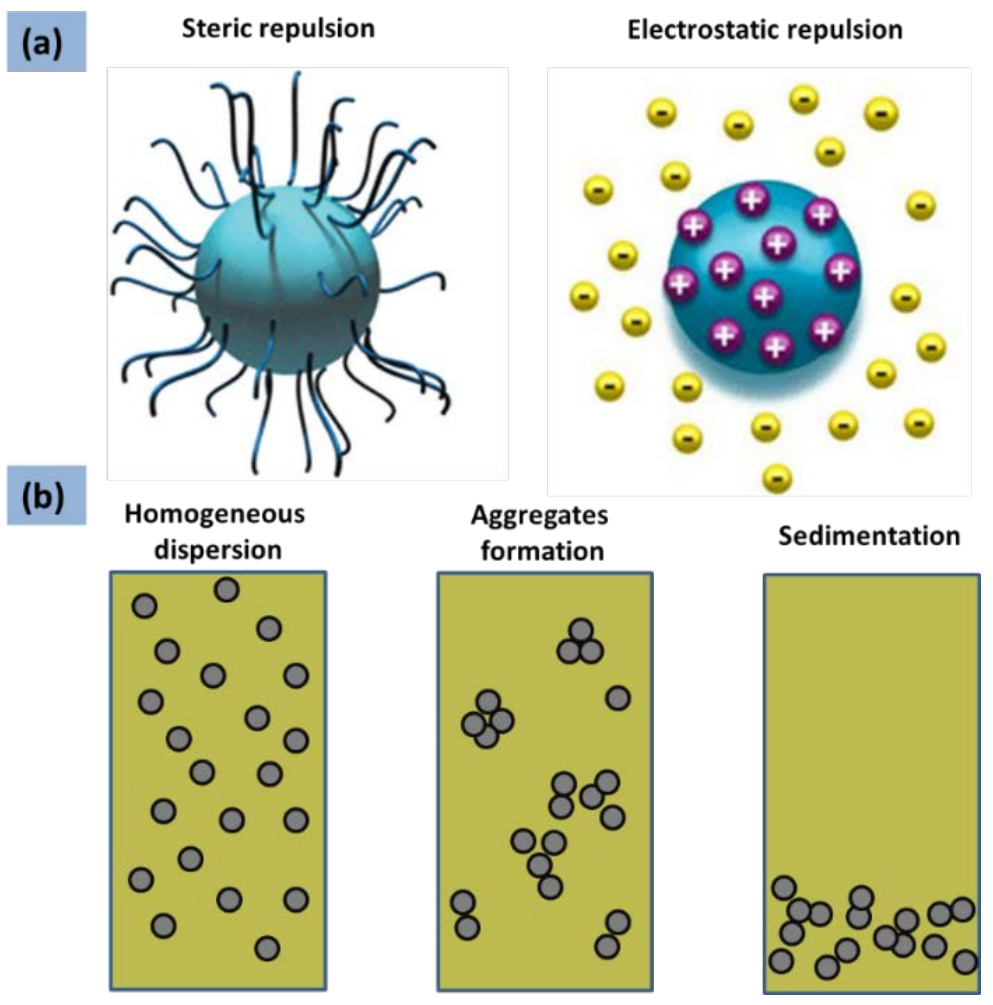

Figure 4. (a) Types of colloidal stabilization [66]. Reproduced with permission from [Yu, W.; Xie, H.], [Journal of Nanomaterials]; published by [Hindawi], [2012]. (b) Particle aggregates formation: as the aggregation proceeds, the particles form larger and larger clusters and sediments. 


\subsection{1. rGO/GO Suspension Stabilization Techniques}

In general, $\mathrm{rGO} / \mathrm{GO}$ nanosheets can be stabilized by either adding a dispersing agent into the solvent or by surface modification (see Table 1, column 3). In the study carried out by Zhao at al. [67], a mildly thermally rGO suspension in PAO6 oil was obtained by using a magnetic stirrer for $2 \mathrm{~h}$ and by subsequent ultra-sonication for $0.5 \mathrm{~h}$ without any dispersing agents. With this method, stability in oil was guaranteed for $25 \mathrm{~h}$ because of the reduced number of oxygen groups of the rGO compared to the pristine GO. According to Ismail et al. [68], click coupling between alkyne-functionalized GO and azido decane leads to the formation of triazole ring-decorated, reduced graphene oxide, which, in virtue of its hydrocarbon tail and after sonication, shows one-month stability in base oil. In the study by Mungse et al. [56], hydroxyl and epoxide groups of graphene oxide were functionalized with alkyl chains constituted by octadecylamine. This results in a one-month stability as the van der Waals forces between the octadecyl chains of the functionalized GO and the apolar chains of the base oil enable a high dispersibility of the additive nanosheets. In other studies [20,52], graphene platelets were modified with stearic and oleic acids as well as with oleic acid only, respectively. As a result, the long hydrocarbon chains of these molecules covering the sheets not only helped disperse the additive in base oil, but also helped prevent the additive sheets from agglomeration as a consequence of a steric hindrance effect resulting from the chains stretching into the oil. In [53], a one-month stable dispersion of rGO in 10W-40 commercial base oil is guaranteed by the long alkyl chain of octadecylamine, which was linked to the carboxylic groups of rGO by means of amide linkages, with thionyl chloride acting as reaction coupler.

As previously mentioned, a parallel strategy to enhance additive stability in oil is the usage of dispersants/surfactants [69,70]. For instance, Ota et al. [69] mixed pristine graphite with a polyisobutylene succinimide dispersant in hydrocarbon media, followed by mechanical exfoliation to obtain a one year-stable dispersion of graphene. Furthermore, the authors highlight the importance of testing the additive in a complex commercial oil formulation, in which compatibility not only with the base oil but also with the other additives included in the final formulation is crucial.

A deeper discussion about the methods of $\mathrm{rGO} / \mathrm{GO}$ suspension stabilization is presented below, along with a detailed description of the stabilization methods reported in the literature for specific dispersions in lubricant base oils.

\subsubsection{Dispersing Agents}

It is a common practice in lubrication to add dispersant molecules that can interact with organic contaminants, generated from aging and oxidation processes, to maintain them in suspension until the filtration point of the lubrication cycle is reached. They reduce the formation of deposits on metal surfaces and inhibit soot agglomeration via stable micelles formation. Therefore, the utilization of dispersing agents is not a novel technique in the attempt to stabilize $\mathrm{rGO} / \mathrm{GO}$ nanosheet suspensions. Dispersants are mainly surfactants with multiple polar groups that enable a better interaction with suspended contaminants [73].

Additionally, the surfactant acts as a barrier against re-aggregation phenomena by providing steric or electrostatic repulsions, depending on its nature. As mentioned in the previous paragraph, one of the most outstanding surfactants for dispersing graphene-like materials in lubricant oils is polyisobutylene succinimide. In 2015, Ota et al. reported, for this surfactant, an excellent stability performance for one year [69]. This long-term stability could be explained by the presence of various functional groups in the dispersant that can form multiple numbers of interactions with nanosheets, as illustrated in Figure 5.

Although dispersant addition seems an optimal method for homogenous suspension, its presence might change the lubricant base oil properties. Surfactants are well known to increase the continuous medium viscosity, which can limit lubricant oil usage. Furthermore, dispersants need to be mixed at high concentrations in the industrial base oil, which leaves them prone to harsh mechanical conditions and oxidation, hence declining their stable performance. 


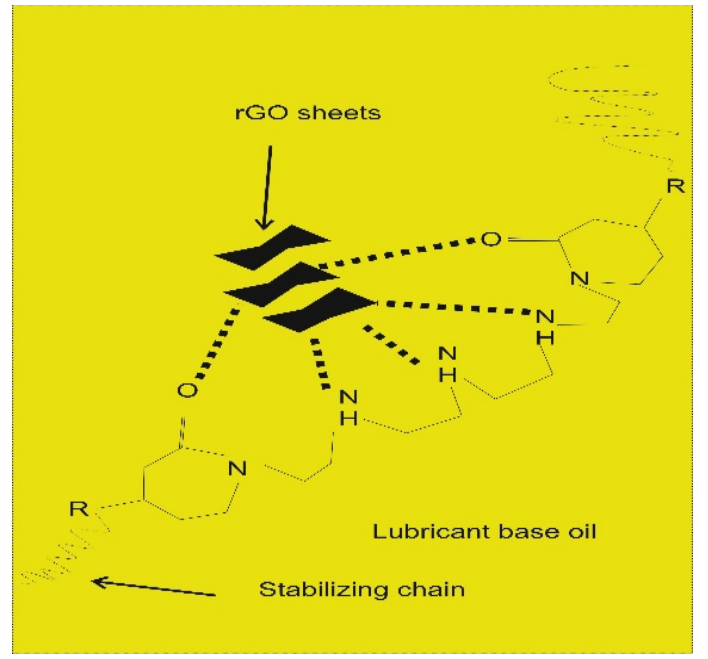

Figure 5. Polyisobutylene succinimide interaction with rGO nanosheets.

Moreover, it is important to distinguish between the utilization of surfactants as a dispersant and their usage as a non-additive surface modifier, which will be discussed in the following section.

\subsection{3. rGO/GO Surface Modification and Functionalization Routes}

In this section, we describe the main approaches reported in the literature for $\mathrm{rGO} / \mathrm{GO}$ modification to improve stability in polar and non-polar media. Graphene has two main derivatives, i.e., GO and rGO, produced through harsh chemical oxidation processes, leaving them with a large number of oxygenated functional groups that cannot be completely removed after reduction [74,75]. The remaining oxygenated groups are present both on basal planes and edges of GO and mainly on the edges of $\mathrm{rGO}$, as illustrated in Figure 6. Oxygen groups on $\mathrm{rGO} / \mathrm{GO}$ pave the way for their functionalization, in contrast to graphene which is considered an inert material. In the following, graphene surface functionalization is reviewed; often there are unexplored results in the field of lubrication; different possibilities for stabilizing graphene are reported, with particular attention paid to dispersion in the hydrophilic and hydrophobic phases.

GO

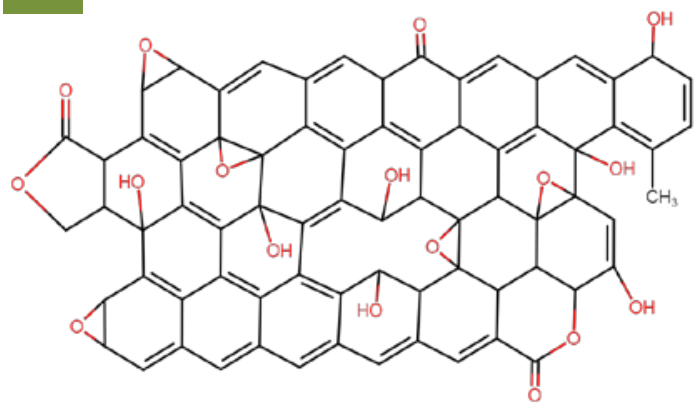

\section{rGO}

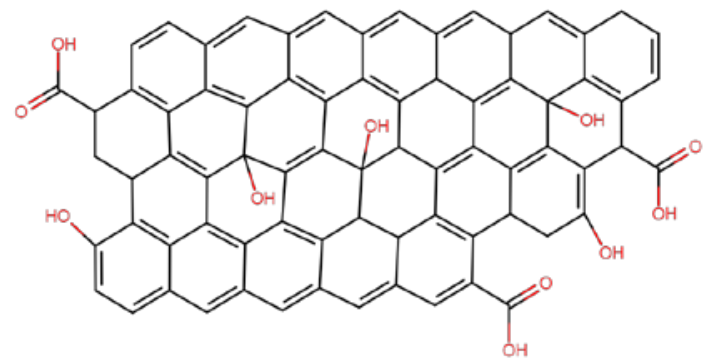

Figure 6. Structural model of single-layer graphene oxide and reduced graphene oxide.

There is an abundance of literature about the functionalization of graphene and its derivatives for enhanced stability in polar and hydrophilic media. However, the research for improving dispersibility in lipophilic solvents is still scarce. Moreover, it should be noted that the functionalization process can be designed to prevent re-staking phenomena and/or increase the interaction with the solvent molecules.

There are different methods to classify the functionalization techniques, which could be based on the nature of the interaction or based on the targeted site or group present on the GO and or rGO 
surface. The latter method seems more practical and comprehensive; that is why we decided to adopt it in order to summarize the data available in the literature.

$\pi$ sites (non-covalent). One beneficial feature of such a modification is that it maintains the native properties of graphene without disturbing $\mathrm{sp}^{2}$ hybridized regions, which are responsible for its high mechanical strength and thermal conductivity [76].

$\pi-\pi$ interactions. The main characteristics of modifiers of this category are the presence of aromatic rings [77], which interact with the $\mathrm{sp}^{2}$ orbitals on the graphene surface. Furthermore, $\pi-\pi$ stacking is more suitable for pristine graphene than rGO and GO due to the absence of oxygen groups that affect $\mathrm{sp}^{2}$ extensions. There is no sufficient information about the performance of such systems in the oil medium, but the nearest analogy could be made with studies performed in the hydrophobic chloroform [78], where pyrene linked to polymers was utilized for graphene dispersion. Additionally, a study was conducted in chloroform using styrene and 2 vinylpyridine copolymers [79] revealing enhanced graphene stability for concentrations ranging from $0.29-0.219 \mathrm{mgL}^{-1}$. The surfactants with aromatic rings have the ability to form $\pi-\pi$ stackings on the graphitic regions of the sheet surface. In this regard, a comparative investigation was performed between sodium dodecyl sulfonate (SDS) and sodium dodecylbenzene sulfonate (SDBS) [80,81]. Both of them are anionic surfactants with an identical alkyl chain length, except for the presence of the aromatic ring on the hydrophilic head of SDBS. The results indicated an enhanced stability for graphene-like materials under different $\mathrm{pH}$ conditions with SDBS. In addition, when SDBS was used as an exfoliating assistant agent, it revealed simultaneous intercalating and stabilizing properties. Furthermore, the stability of graphene exfoliated in the presence of SDBS was higher in the hydrophobic chloroform than in water [10]. However, this is contradictory, since SDBS is mainly hydrophilic, showing a high hydrophilic-lipophilic balance (HLB $=30)$.

Cation- $\pi$ interactions. This method depends on the interactions between the quadrupole moment of the aromatic ring and a positive charge [82,83].

Hydroxyl groups. Tri-alkoxy groups (covalent). In this method, a reaction is triggered between hydroxyl groups and tri-alkoxy groups linked to silanes [84]. The resulted modified GO showed enhanced stability in water.

Polar groups (non-covalent). These interactions depend on the formation of hydrogen bonds between the hydroxyl groups of graphene oxide and the oxygen groups in the modifier, as it was reported that hydrogen bonding contributed to the interaction between $\mathrm{GO}$ and single-stranded nucleic acids such as deoxyribonucleic acid (DNA) and ribonucleic acid (RNA) [85].

Epoxy (covalent). The functionalization of the graphene oxide surface with epoxy groups is more favorable with respect to other oxygen groups because of their central position. The activation of epoxy groups of GO is initiated by nucleophilic reagents, including amines for epoxy ring-opening [86]. Another root for modification is the use of organosulfur compounds such as potassium thioacetate [87].

Carboxylic group (covalent). This group is considered a common target for further GO and rGO modification, in particular with the aim of improving stability in hydrocarbon solvents. The aim of this modification is to form either amides or esters for enhanced reactivities. A common activation agent is thionyl chloride $\left(\mathrm{SOCl}_{2}\right)$ [88]. After this step, amides or esters bonds could be formed with amine or alcohol groups, respectively. This method seems to be superior with respect to other methods when considering dispersion in oils, due to the possibility of grafting alkylated modifiers on the sheets. As also mentioned previously, organic moieties and octadecylamine were used to produce alkylated rGO [56,68], and the tribological results indicated the formation of a relatively stable dispersion in commercial engine oil. They also exhibited a stable suspension for a controlled period of one month with a rGO concentration of $0.02 \mathrm{mg} \mathrm{mL}^{-1}$.

In earlier studies, the characterization of different alkyl amines with variable chain lengths $(\mathrm{Cn}=$ $8,12,18)$ to modify GO was performed. It was observed that the dispersibility of alkylated graphene in hydrocarbon solvents increased by increasing the chain length, which indicates that a higher interaction with the solvent provided better stability [89]. 
Adsorption on different sites. Hydrophobic interaction with alkyls (non-covalent). This is an alternative route for pristine G, rGO and GO stabilization, which consists of the non-covalent interaction and adsorption of the aliphatic part of amphiphilic molecules (surfactants) with the graphene surface, driven by van der Waals forces [90]. An example of such interactions was confirmed by conductometric surfactant titration [91]. The study reported the adsorption of SDS onto rGO. It was concluded that the adsorption process proceeds through four stages, depending on the surfactant concentration. In the first stage, when the SDS concentration is less than $12 \mu \mathrm{M}$ in the bulk solution, SDS monomers initiate to be adsorbed on the rGO surface. Following this stage, at a concentration of $\sim 12 \mu \mathrm{M}$, a monolayer is formed, completely covering the rGO surface. Additionally, the critical surface aggregation concentration (CSAC) for the surface hemicylederical micelles formation on rGO is around $1.5 \mathrm{mM}$, which is considered a saturation concentration, and any increment in this SDS concentration leads to micelles formation in the bulk phase. Such a system showed superior stability for two years with an SDS concentration of $40 \mu \mathrm{M}$, e.g., two orders of magnitude below CSAC. What is more, it could be observed that the utilization of this technique in the oil phase would favor the second stage of adsorption, as the hydrophilic parts of the surfactant have no affinity for the bulk phase.

Other types of surfactants, including the non-ionic oleic and stearic acids, were utilized as modifiers [51]. The mechanism of these surfactants consists of providing steric barriers around graphene in order to limit aggregation phenomena between nanosheets in industrial base oils, which resulted in improved stability for rGO concentrations of up to $0.4 \mathrm{wt} \%$.

In-situ synthesis of nanoparticles (non-covalent). This technique is based on the formation of relatively smaller nanoparticles on the surface of $\mathrm{rGO} / \mathrm{GO}$ to act as re-staking inhibitors. Different studies adopted different nanoparticles, including magnesium phyllosilicate [92], yet with a common goal, e.g., to improve stability in water. However, to the best of our knowledge, still no studies can be found with oil as a bulk phase. Thus, further investigations are required.

\subsubsection{Description of the Stability Methods for Dispersion in Lubricant Base Oils}

The number of studies on stability utilizing $\mathrm{G}$ in lubricant oil additives is still limited. In this section, data available in the literature regarding the techniques thus far utilized for stabilization are reported.

Lin et al., 2011, chemically modified graphene in reactions with stearic and oleic acids under reflux conditions [20]. The modified graphene plates (MGP) revealed an improvement in stability in base oil confirmed by ultraviolet-visible spectroscopy (UV-Vis). A tribological enhancement occurred when only $0.075 \mathrm{wt} \%$ of MGP dispersed in base oil led to improvements in the wear resistance and load-carrying capacity of the equipment. In a different study, Zhang et al., 2011, modified rGO with only oleic acid and with a lower range of optimum concentrations of $0.02-0.06 \mathrm{wt} \%$, which contributed to a friction and wear reduction of $17 \%$ and $14 \%$, respectively [52]. Furthermore, Ali et al., 2018 utilized oleic acid as a dispersing agent by mixing 2\% of it with rGO and lubricant oil to form a stable mixture [70]. The mixture remained homogenous for a measured period of one month. The friction and wear dropped considerably by $29 \%-35 \%$ and $22 \%-29 \%$ respectively, at a $0.4 \mathrm{wt} \%$ graphene concentration.

Regarding covalent modification, Mungse et al., 2015 designed a single-step approach to link the long alkyl chain of octadecyl molecules to the basal plane of graphene oxide in a simultaneous reduction of oxygen [56]. The reported controlled stability is for one month in base oil (Figure 7) due to van der Waals interactions between the octadecyl chains grafted on graphene and the alkyl chains of lube oil, with a $25 \%$ reduction of both friction and wear. Another covalent functionalization of GO was conducted by Ismail et al., 2017, with aromatic moieties, by using Copper-Catalyzed Azide-Alkyne Cycloaddition (CuAAC) via Click chemistry. The results showed that with only 0.01 $\mathrm{wt} \%$ of functionalized graphene added to the base oil, friction and wear was significantly reduced by $16 \%$ and $30 \%$, respectively [68]. 


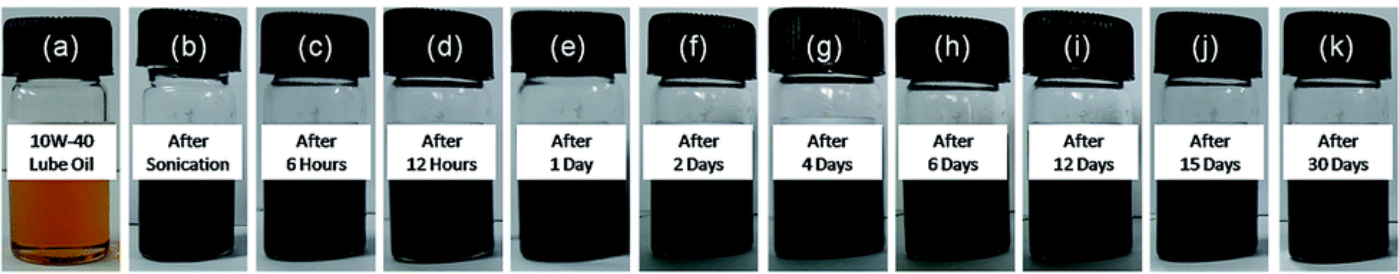

Figure 7. Photos of (a) 10W-40 lube oil and (b-k) dispersions of GO-ODA nanosheets in 10W-40 lube oil at different times (up to one month). The time is reported on each bottle. The concentration of GO-ODA nanosheets: $0.04 \mathrm{mg} \mathrm{mL}^{-1}$ [56]. [RSC Adv., 2015, 5, 25565-25571]-Reproduced with permission of The Royal Society of Chemistry.

Ota et al., 2015, utilized commercial polyisobutylene succinic imide dispersant in various lube oils to disperse $0.5 \mathrm{wt} \%$ of graphene. The results indicated a superior stability for one year with a positive enhancement in both friction and wear reduction. It should be noted that this dispersant needs to be added in relatively greater amounts to show its positive effects [69].

An alternative route to modify graphene is to change its morphology, as was indicated by Dou et al., 2016. Their method consists of crumpling $\mathrm{G}$ sheets into ball-like particles by a capillary compression approach. The crumpled balls revealed a high stability for $20 \mathrm{~h}$ in contrast to rGO plane sheets. This method originates from the analogy according to which crumpled papers do not stick together. Tribological tests of base oil mixed with these balls showed extreme wear reduction of $\sim 85 \%$ and friction reduction of $20 \%$, regardless of their relatively big average size of $\sim 500 \mathrm{~nm}$ [70]. Table 1 summarizes literature studies utilizing $\mathrm{rGO} / \mathrm{GO}$ as tribo-additives in different base oils, including the adopted modification methods, the measured stability and the tribo-conditions.

Eventually, the stability of GO in commercial oil can also be enhanced through a thermal reduction treatment at $700{ }^{\circ} \mathrm{C}$, as reported by Zhao et al. [67].

\section{Discussion}

From the conclusions of the different studies cited above, it can be postulated that $\mathrm{rGO} / \mathrm{GO}$ nanosheets can reduce wear and friction. Wear reduction is obtained by deposition and film formation, while friction reduction is related more to the shear and lamination of the sheets on the contacting surfaces. Nevertheless, the two phenomena are interrelated and work in sync. In this context, it is of high importance to form a homogenous suspension for a continuous nanosheets supply after deposition and shearing (Figure 8).

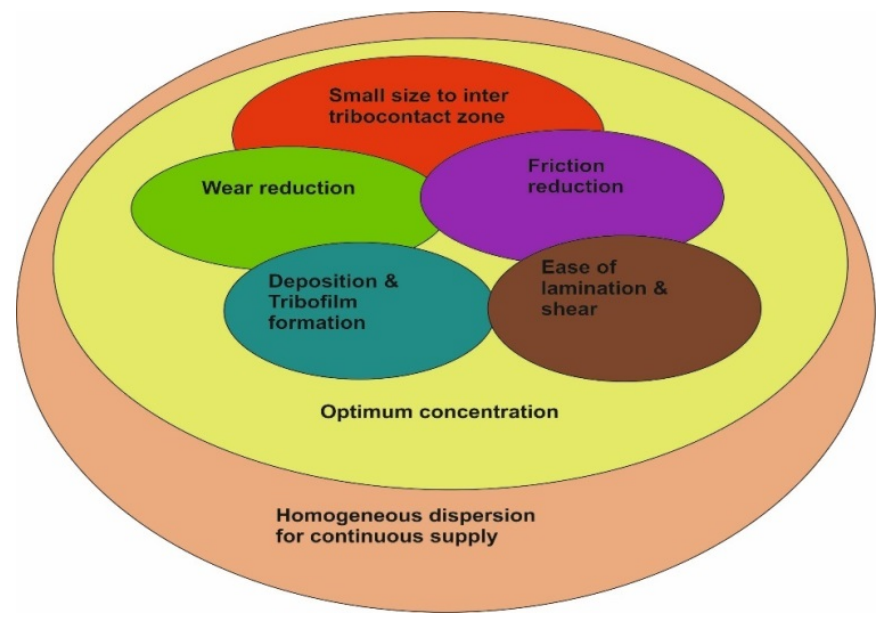

Figure 8. Relationships between the different factors contributing to the best tribological results. 
On the other hand, despite the consistent performance of $\mathrm{rGO} / \mathrm{GO}$ nanolubricants in reducing wear and friction, there are still remaining obstacles to overcome. Moreover, the fact that each new system deserves renewed attention, and more precisely that each graphene/base combination needs a dedicated effort, e.g., nanocarbons used in different laboratories do not have precisely the same surface properties, does not help. Additionally, anti-friction and anti-wear additives are only a part of the delicate balance of components that will constitute the final formulation. For industrialization, it would be desirable that additives do not modify the base rheological properties. Indeed, otherwise, a re-modulation of the entire formulation would probably be required. This aspect is almost never explored in the literature, in which little attention has been devoted to the rheology of the formulations or to the analysis of completely formulated oils. In particular, aspects such as the tendency to aggregate as well as the optimum concentration remain hot topics. The reaggregation of nanosheets in lubricating oils is one of the most urgent issues. The two-dimensional rGO/GO nanosheets exhibit a very high surface energy with high diffusive properties, enabling them to form a protective layer and helping mend the micro-cracks on the rubbing surface. However, these properties are also the main cause of poor suspension. The reaggregation of the sheets can even deteriorate the pure base oil properties due to the formation of a non-equivalent distribution of the sheets themselves, as conceptualized in Figure 9 (compare Figure 9a,b). Another important issue in order to ensure the best tribological performance is to find the optimum additive concentration. Too few nanosheets may not be sufficient to cover the rubbing surfaces, whereas too many sheets present in the oil can increase reaggregation and the formation of a non-continuous oil film due to large aggregates, as shown in Figure 9c. Regarding enhanced stability, the rGO/GO surface modification seems more attractive than using a dispersing agent because of the possible effects of the dispersant on the bulk properties of the lubricating oil. For instance, the addition of dispersants can increase the viscosity and could affect the viscosity index of the oil, which is a crucial parameter for oil usage. Additionally, it can affect the nanosheet's capability to diffuse towards the interacting surfaces, as a consequence of the increased viscosity.

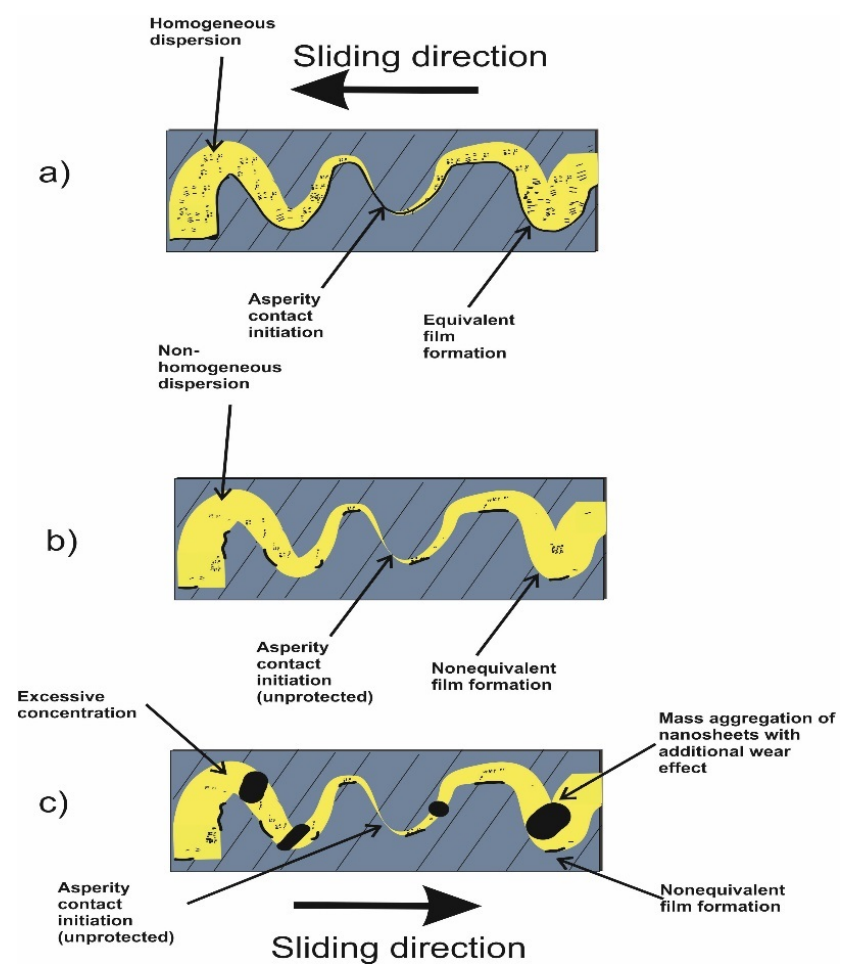

Figure 9. (a) rGO/GO suspension and tribofilm formation between two rubbing surfaces sliding in opposite directions, (b) homogenous suspension with the optimum concentration and (c) non-homogenous state, excessive concentration. 
More generally, rGO/GO nanoadditives are still in need of a more comprehensive study and characterization regarding the long-term stability and working mechanism.

In this scenario, a recent way, which inherently possesses the solution to many of the critical aspects listed above, consists of the use of carbon quantum dots (CQDs), as shown in Figure 10. CQDs are surface-functionalized and easily modifiable $0 \mathrm{D}$ material, which can be easily dispersed and is able to repair wear scars and form tribofilms, above all by not significantly changing the oil color and rheological properties of the oil [93].
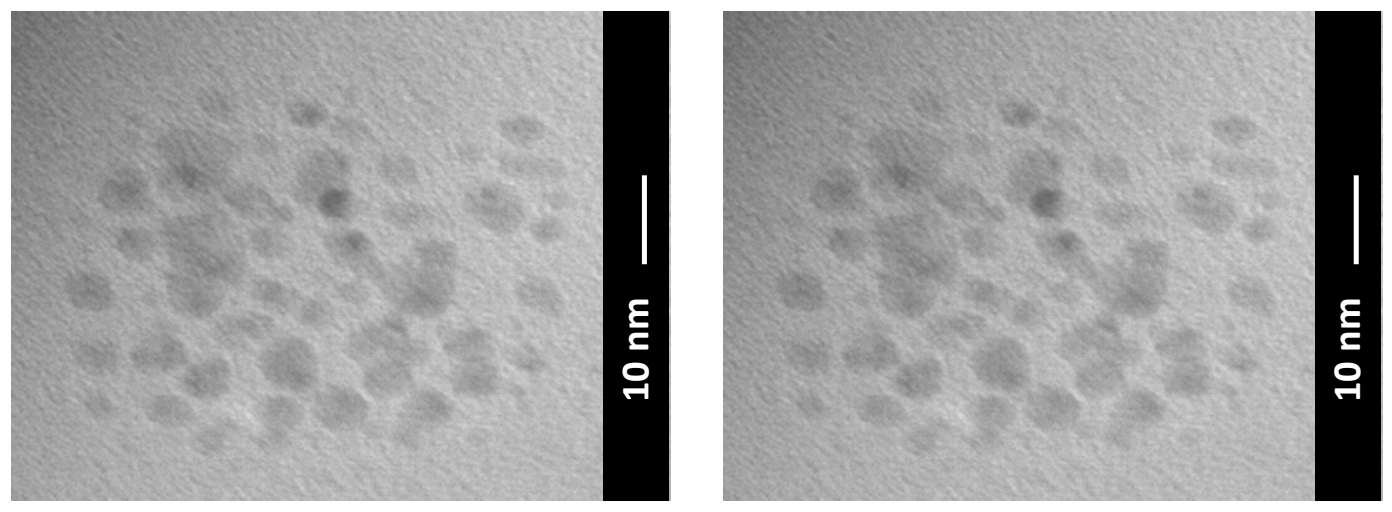

Figure 10. Transmission electron microscope image of CQDS formed by a facile hydrothermal carbonization of citric acid at a relatively low temperature at $200{ }^{\circ} \mathrm{C}$.

\section{Conclusions}

This review, after an introduction of the main lubrication mechanisms in the presence of NPs, focuses on the adoption of rGO/GO in the field of tribology, and, finally, deals with a critical review on the nanoparticles' optimization and functionalization to give a stable and homogenous suspension. It can be postulated that $\mathrm{rGO} / \mathrm{GO}$ nanosheets can reduce wear and friction. Wear reduction is obtained by deposition and film formation, while friction reduction is more related to the shear and lamination of the sheets on the contacting surfaces. Nevertheless, the two phenomena are interrelated and work in sync. In this context, it is of high importance to form a homogenous suspension for a continuous nanosheets supply after deposition and shearing. On the other hand, despite the consistent performance of $\mathrm{rGO} / \mathrm{GO}$ nanolubricants in reducing wear and friction, there are still remaining obstacles to overcome. Moreover, the fact that each new system deserves renewed attention, and more precisely that each graphene/base combination needs a dedicated effort, e.g., nanocarbons used in different laboratories do not have precisely the same surface properties, does not help. Additionally, anti-friction and anti-wear additives are only a part of the delicate balance of components that will constitute the final formulation. For industrialization, it would be desirable for additives not to modify the base rheological properties. Indeed, otherwise, a re-modulation of the entire formulation would probably be required. More generally, rGO/GO nanoadditives are still in need of a more comprehensive study and characterization regarding the long-term stability and working mechanism.

Author Contributions: Conceptualization, M.S. and A.S.; methodology, M.S.; investigation, W.A.A.M.; writing-original draft preparation D.S. and W.A.A.M.; writing-review and editing, D.S.; supervision, M.S.; project administration, M.S. and A.S.; funding acquisition, M.S. and A.S. All authors have read and agreed to the published version of the manuscript.

Funding: This research was supported by National Operative Programme for Companies and Competitiveness 2014-2020-Horizon 2020, funded by the European Union (Rilub SPA, project leader. Project n. F/050190/01-02/×32-Introduzione di nanotecnologie e materiali avanzati nel settore industrial delle trasmissioni meccaniche di Potenza e, in particolare, dei lubrificanti per gli ingranaggi-INNOLUBE).

Conflicts of Interest: The authors declare no conflict of interest The funders had no role in the design of the study; in the collection, analyses, or interpretation of data; in the writing of the manuscript, or in the decision to publish the results. 


\section{References}

1. Bowden, F.P.; Gregory, J.N.; Tabor, D. Lubrication of metal surfaces by fatty acids. Nature 1945, 156, 97-101.

2. Spikes, H. The history and mechanisms of ZDDP. Tribol. Lett. 2004, 17, 469-489.

3. Forbes, E.S. Antiwear and extreme pressure additives for lubricants. Tribology 1970, 3, 145-152.

4. Sudeep, P.M.; Taha-Tijerina, J.; Ajayan, P.M.; Narayanan, T.N.; Anantharaman, M.R. Nanofluids based on fluorinated graphene oxide for efficient thermal management. RSC Adv. 2014, 4, 24887-24892.

5. Taha-Tijerina, J.; Aviña, K.; Diabb, J.M. Tribological and Thermal Transport Performance of $\mathrm{SiO}_{2}-\mathrm{Based}$ Natural Lubricants. Lubricants 2019, 7, 71.

6. Bakunin, V.N.; Suslov, A.Y.; Kuzmina, G.N.; Parenago, O.P.; Topchiev, A.V. Synthesis and application of inorganic nanoparticles as lubricant components-A review. J. Nanopart. Res. 2004, 6, 273-284.

7. Zhang, W.; Demydov, D.; Jahan, M.P.; Mistry, K.; Erdemir, A.; Malshe, A.P. Fundamental understanding of the tribological and thermal behavior of $\mathrm{Ag}-\mathrm{MoS}_{2}$ nanoparticle-based multi-component lubricating system. Wear 2012, 288, 9-16.

8. Jiao, D.; Zheng, S.; Wang, Y.; Guan, R.; Cao, B. The tribology properties of alumina/silica composite nanoparticles as lubricant additives. Appl. Surf. Sci. 2011, 257, 5720-5725.

9. Sarno, M.; Senatore, A.; Cirillo, C.; Petrone, V.; Ciambelli, P. Oil lubricant tribological behaviour improvement through dispersion of few layer graphene oxide. J. Nanosci. Nanotechnol. 2014, 14, 4960-4968.

10. Spikes, H. Friction modifier additives. Tribol. Lett. 2015, 60, 5.

11. Seiler, S.; Halbig, C.E.; Grote, F.; Rietsch, P.; Börrnert, F.; Kaiser, U.; Meyer, B.; Eigler, S. Effect of friction on oxidative graphite intercalation and high-quality graphene formation. Nat. Commun. 2018, 9, 836. [PubMed]

12. Konios, D.; Stylianakis, M.M.; Stratakis, E.; Kymakis, E. Dispersion behaviour of graphene oxide and reduced graphene oxide. J. Colloid Interface Sci. 2014, 430, 108-112.

13. Pei, S.; Cheng, H.M. The reduction of graphene oxide. Carbon 2012, 50, 3210-3228.

14. Li, J.; Zeng, X.; Ren, T.; Van der Heide, E. The preparation of graphene oxide and its derivatives and their application in bio-tribological systems. Lubricants 2014, 2, 137-161.

15. Lee, C.; Wei, X.; Kysar, J.W.; Hone, J. Measurement of the elastic properties and intrinsic strength of monolayer graphene. Science 2008, 321, 385-388.

16. Berman, D.; Erdemir, A.; Sumant, A.V. Graphene: A new emerging lubricant. Mater. Today 2014, 17, 31-42.

17. Van, N.H. Effect of long-chain alkylamine on the dispersibility and tribological properties of alkyl-graphene in lubricant oil. Vietnam J. Sci. Technol. 2018, 56, 163-173.

18. Geim, A.K. Graphene: Status and prospects. Science 2009, 324, 1530-1534.

19. Schiøtz, J.; Jacobsen, K.W. A maximum in the streght of nanocrystalline copper. Science 2003, 301, 1357-1359.

20. Lin, J.; Wang, L.; Chen, G. Modification of graphene platelets and their tribological properties as a lubricant additive. Tribol. Lett. 2011, 41, 209-215.

21. Kim, D.; Archer, L.A. Nanoscale organic-inorganic hybrid lubricants. Langmuir 2011, 27, 3083-3094. [PubMed]

22. Yu, F.; Chen, Y.; Liang, X.; Xu, J.; Lee, C.; Liang, Q.; Tao, P.; Deng, T. Dispersion stability of thermal nanofluids. Prog. Nat. Sci. Mater. 2017, 27, 531-542.

23. Qin, Z.; Taylor, M.; Hwang, M.; Bertoldi, K.; Buehler, M.J. Effect of wrinkles on the surface area of graphene: Toward the design of nanoelectronics. Nano Lett. 2014, 14, 6520-6525.

24. Shen, J.; Hu, Y.; Li, C.; Qin, C.; Ye, M. Synthesis of amphiphilic graphene nanoplatelets. Small 2009, 5, 82-85. [PubMed]

25. Yu, H.L.; Yi, X.U.; Shi, P.J.; Xu, B.S.; Wang, X.L.; Qian, L.I.U. Tribological properties and lubricating mechanisms of Cu nanoparticles in lubricant. Trans. Nonferr. Metals Soc. 2008, 18, 636-641.

26. Tomala, A.; Vengudusamy, B.; Ripoll, M.R.; Suarez, A.N.; Remškar, M.; Rosentsveig, R. Interaction between selected $\mathrm{MoS}_{2}$ nanoparticles and ZDDP tribofilms. Tribol. Lett. 2015, 59, 26.

27. Viesca, J.L.; Battez, A.H.; González, R.; Chou, R.; Cabello, J.J. Antiwear properties of carbon-coated copper nanoparticles used as an additive to a polyalphaolefin. Tribol. Int. 2011, 44, 829-833.

28. Sayuti, M.; Erh, O.M.; Sarhan, A.A.; Hamdi, M. Investigation on the morphology of the machined surface in end milling of aerospace AL6061-T6 for novel uses of $\mathrm{SiO}_{2}$ nanolubrication system. J. Clean. Prod. 2014, 66, 655-663.

29. Liu, G.; Li, X.; Qin, B.; Xing, D.; Guo, Y.; Fan, R. Investigation of the mending effect and mechanism of copper nano-particles on a tribologically stressed surface. Tribol. Lett. 2004, 17, 961-966. 
30. Tao, X.; Jiazheng, Z.; Kang, X. The ball-bearing effect of diamond nanoparticles as an oil additive. J. Phys. D Appl. Phys. 1996, 29, 2932.

31. Dassenoy, F. Application I: Nanolubricants. In Nanosciences and Nanotechnology: Evolution or Revolution? 1st ed.; Lourtioz, J.M., Lahmani, M., Dupas-Haeberlin, C., Hesto, P., Eds.; Springer: Cham, Switzerland, 2015; Volume 2, pp. 175-181.

32. Gulzar, M.; Masjuki, H.H.; Kalam, M.A.; Varman, M.; Zulkifli, N.W.M.; Mufti, R.A.; Zahid, R. Tribological performance of nanoparticles as lubricating oil additives. J. Nanopart. Res. 2016, 18, 223.

33. Laad, M.; Jatti, V.K.S. Titanium oxide nanoparticles as additives in engine oil. J. King Saud Univ. Sci. 2018, 30, 116-122.

34. Khadem, M.; Penkov, O.V.; Pukha, V.E.; Maleyev, M.V.; Kim, D.E. Ultra-thin carbon-based nanocomposite coatings for superior wear resistance under lubrication with nano-diamond additives. RSC Adv. 2016, 6, 56918-56929.

35. Padgurskas, J.; Rukuiza, R.; Prosyčevas, I.; Kreivaitis, R. Tribological properties of lubricant additives of Fe, $\mathrm{Cu}$ and Co nanoparticles. Tribol. Int. 2013, 60, 224-232.

36. Demas, N.G.; Timofeeva, E.V.; Routbort, J.L.; Fenske, G.R. Tribological effects of BN and $\mathrm{MoS}_{2}$ nanoparticles added to polyalphaolefin oil in piston skirt/cylinder liner tests. Tribol. Lett. 2012, 47, 91-102.

37. Nallasamy, P.; Saravanakumar, N.; Nagendran, S.; Suriya, E.M.; Yashwant, D. Tribological investigations on $\mathrm{MoS}_{2}$-based nanolubricant for machine tool slideways. Proc. Inst. Mech. Eng. 2015, 229, 559-567.

38. Wu, L.; Zhang, Y.; Yang, G.; Zhang, S.; Yu, L.; Zhang, P. Tribological properties of oleic acid-modified zinc oxide nanoparticles as the lubricant additive in poly-alpha olefin and diisooctyl sebacate base oils. RSC Adv. 2016, 6, 69836-69844.

39. Chen, Y.; Zhang, Y.; Zhang, S.; Yu, L.; Zhang, P.; Zhang, Z. Preparation of nickel-based nanolubricants via a facile in situ one-step route and investigation of their tribological properties. Tribol. Lett. 2013, 51, 73-83.

40. Wu, J.F.; Zhai, W.S.; Jie, G.F. Preparation and tribological properties of WS2 nanoparticles modified by trioctylamine. Proc. Inst. Mech. Eng. 2009, 223, 695-703.

41. Jifen, W.; Wensheng, Z.; Guifen, J. Preparation and tribological properties of tungsten disulfide hollow spheres assisted by methyltrioctylammonium chloride. Tribol. Int. 2010, 43, 1650-1658.

42. Flores-Castañeda, M.; Camps, E.; Camacho-López, M.; Muhl, S.; García, E.; Figueroa, M. Bismuth nanoparticles synthesized by laser ablation in lubricant oils for tribological tests. J. Alloys Compd. 2015, 643, $67-70$.

43. Kato, H.; Komai, K. Tribofilm formation and mild wear by tribo-sintering of nanometer-sized oxide particles on rubbing steel surfaces. Wear 2007, 262, 36-41.

44. Zhao, F.; Bai, Z.; Fu, Y.; Zhao, D.; Yan, C. Tribological properties of serpentine, $\mathrm{La}(\mathrm{OH})_{3}$ and their composite particles as lubricant additives. Wear 2012, 288, 72-77.

45. Song, X.; Zheng, S.; Zhang, J.; Li, W.; Chen, Q.; Cao, B. Synthesis of monodispersed $\mathrm{ZnAl}_{2} \mathrm{O}_{4}$ nanoparticles and their tribology properties as lubricant additives. Mater. Res. Bull. 2012, 47, 4305-4310.

46. Grierson, D.S.; Carpick, R.W. Nanotribology of carbon-based materials. Nano Today 2007, 2, $12-21$.

47. Ali, M.K.A.; Xianju, H.; Turkson, R.F.; Peng, Z.; Chen, X. Enhancing the thermophysical properties and tribological behaviour of engine oils using nano-lubricant additives. RSC Adv. 2016, 6, 77913-77924.

48. Lee, C.G.; Hwang, Y.J.; Choi, Y.M.; Lee, J.K.; Choi, C.; Oh, J.M. A study on the tribological characteristics of graphite nano lubricants. Int. J. Precis. Eng. Manuf. 2009, 10, 85-90.

49. Abdullah, M.I.H.C.; Abdollah, M.F.B.; Amiruddin, H.; Tamaldin, N.; Nuri, N.M. Effect of hBN/Al $2 \mathrm{O}_{3}$ nanoparticle additives on the tribological performance of engine oil. J. Qual. Technol. 2014, 66, 1-6.

50. Xu, Y.; Peng, Y.; Dearn, K.D.; Zheng, X.; Yao, L.; Hu, X. Synergistic lubricating behaviors of graphene and $\mathrm{MoS}_{2}$ dispersed in esterified bio-oil for steel/steel contact. Wear 2015, 342, 297-309.

51. Eswaraiah, V.; Sankaranarayanan, V.; Ramaprabhu, S. Graphene-based engine oil nanofluids for tribological applications. ACS Appl. Mater. Interfaces 2011, 3, 4221-4227.

52. Zhang, W.; Zhou, M.; Zhu, H.; Tian, Y.; Wang, K.; Wei, J.; Ji, F.; Li, X.; Li, Z.; Zhang, P.; et al. Tribological properties of oleic acid-modified graphene as lubricant oil additives. J. Phys. D Appl. Phys. 2011, 44, 20.

53. Mungse, H.P.; Khatri, O.P. Chemically functionalized reduced graphene oxide as a novel material for reduction of friction and wear. J. Phys. Chem. C 2014, 118, 14394-14402.

54. Kim, K.S.; Lee, H.J.; Lee, C.; Lee, S.K.; Jang, H.; Ahn, J.H.; Kim, J.H.; Lee, H.J. Chemical vapor deposition-grown graphene: The thinnest solid lubricant. ACS Nano 2011, 5, 5107-5114. 
55. Berman, D.; Erdemir, A.; Sumant, A.V. Few layer graphene to reduce wear and friction on sliding steel surfaces. Carbon 2013, 54, 454-459.

56. Mungse, H.P.; Kumar, N.; Khatri, O.P. Synthesis, dispersion and lubrication potential of basal plane functionalized alkylated graphene nanosheets. RSC Adv. 2015, 5, 25565-25571.

57. Bart, J.C.; Gucciardi, E.; Cavallaro, S. Biolubricants: Science and Technology, 1st ed.; Woodhead Publishing: Cambridge, UK, 2013; pp. 13-15.

58. Patel, J.; Kiani, A. Effects of Reduced Graphene Oxide (rGO) at Different Concentrations on Tribological Properties of Liquid Base Lubricants. Lubricants 2019, 7, 11.

59. Liñeira del Río, J.M.; López, E.R.; Fernández, J.; García, F. Tribological properties of dispersions based on reduced graphene oxide sheets and trimethylolpropane trioleate or PAO 40 oils. J. Mol. Liquids 2019, 274, 568-576.

60. Gupta, B.N.; Kumar, N.; Panda, K.; Dash, S.; Tyagi, A.K. Energy efficient reduced graphene oxide additives: Mechanism of effective lubrication and antiwear properties. Sci. Rep. 2016, 6, 18372.

61. Ismail, N.A.; Bagheri, S. Lube Oil Wear Reduction via Organic Tribofilms. Lubricants 2017, 5, 30.

62. Li, Y.; Zhao, J.; Tang, C.; He, Y.; Wang, Y.; Chen, J.; Mao, J.; Zhou, Q.; Wang, B.; Wei, F.; et al. Highly Exfoliated Reduced Graphite Oxide Powders as Efficient Lubricant Oil Additives. Adv. Mater. Interfaces 2016, 3, 1600700.

63. Schlüter, B.; Mülhaupt, R.; Kailer, A. Synthesis and Tribological Characterization of Stable Dispersions of Thermally Reduced Graphite Oxide. Tribol. Lett. 2014, 53, 353-363.

64. Mungse, P.H.; Gupta, K.; Singh, R.; Sharma, O.P.; Sugimura, H.; Khatri, O.P. Alkylated graphene oxide and reduced graphene oxide: Grafting density, dispersion stability to enhancement of lubrication properties. J. Colloid Interface Sci. 2019, 541, 150-162.

65. Aldana, P.U. Tungsten disulfide nanoparticles as lubricant additives for the automotive industry. Ph.D. Thesis, Université de Lyon, Lyon, France, 2016.

66. Yu, W.; Xie, H. A review on nanofluids: Preparation, stability mechanisms, and applications. J. Nanomater. 2012, 2012, 17.

67. Zhao, J.; Li, Y.; Wang, Y.; Mao, J.; He, Y.; Luo, J. Mild thermal reduction of graphene oxide as a lubrication additive for friction and wear reduction. RSC Adv. 2017, 7, 1766-1770.

68. Ismail, N.A.; Bagheri, S. Highly oil-dispersed functionalized reduced graphene oxide nanosheets as lube oil friction modifier. Mater. Sci. Eng. B Adv. 2017, 222, 34-42.

69. Ota, J.; Hait, S.K.; Sastry, M.I.S.; Ramakumar, S.S.V. Graphene dispersion in hydrocarbon medium and its application in lubricant technology. RSC Adv. 2015, 5, 53326-53332.

70. Ali, M.K.A.; Xianjun, H.; Abdelkareem, M.A.; Gulzar, M.; Elsheikh, A.H. Novel approach of the graphene nanolubricant for energy saving via anti-friction/wear in automobile engines. Tribol. Int. 2018, 124, $209-229$.

71. Dou, X.; Koltonow, A.R.; He, X.; Jang, H.D.; Wang, Q.; Chung, Y.W.; Huang, J. Self-dispersed crumpled graphene balls in oil for friction and wear reduction. Proc. Natl. Acad. Sci. USA 2016, 113, 1528-1533.

72. Overview of DLVO Theory. Available online: http://www.colloid.ch/index.php?name=dlvo (accessed on 5 January 2020).

73. Minami, I. Molecular science of lubricant additives. Appl. Sci. 2017, 7, 445.

74. Stankovich, S.; Dikin, D.A.; Piner, R.D.; Kohlhaas, K.A.; Kleinhammes, A.; Jia, Y.; Wu, Y.; Nguyen, S.T.; Ruoff, R.S. Synthesis of graphene-based nanosheets via chemical reduction of exfoliated graphite oxide. Carbon 2007, 45, 1558-1565.

75. Lonkar, S.P.; Abdala, A.A. Applications of graphene in catalysis. J. Thermodyn. Catal. 2014, 5, 1-132.

76. Jeon, I.Y.; Chang, D.W.; Kumar, N.A.; Baek, J.B. Functionalization of carbon nanotubes. In Carbon Nanotubes-Polymer Nanocomposites, 1st ed.; Yellampalli, S., Ed.; IntechOpen: Shanghai, China, 2011; pp. 91-109.

77. Grimme, S. Do special noncovalent $\pi-\pi$ stacking interactions really exist? Angew. Chem. 2008, 47, 3430-3434.

78. Wang, H.; Chen, Z.; Xin, L.; Cui, J.; Zhao, S.; Yan, Y. Synthesis of pyrene-capped polystyrene by free radical polymerization and its application in direct exfoliation of graphite into graphene nanosheets. J. Polym. Sci. 2015, 53, 2175-2185.

79. Popescu, M.T.; Tasis, D.; Tsitsilianis, C. Ionizable star copolymer-assisted graphene phase transfer between immiscible liquids: Organic solvent/water/ionic liquid. ACS Macro Lett. 2014, 3, 981-984.

80. Karachevtsev, V.A.; Glamazda, A.Y.; Plokhotnichenko, A.M.; Leontiev, V.S.; Linnik, A.S. Comparative study on protection properties of anionic surfactants (SDS, SDBS) and DNA covering of single-walled carbon nanotubes against $\mathrm{pH}$ influence: Luminescence and absorption spectroscopy study. Mater. Sci. Eng. C 2011, $42,41-46$. 
81. Song, Y.; Lee, H.; Ko, J.; Ryu, J.; Kim, M.; Sohn, D. Preparation and characterization of surfactant-exfoliated graphene. J. Korean Chem. Soc. 2014, 35, 2009.

82. Gallivan, J.P.; Dougherty, D.A. Cation- $\pi$ interactions in structural biology. Proc. Natl. Acad. Sci. USA 1999, 96, 9459-9464.

83. Jeong, S.Y.; Kim, S.H.; Han, J.T.; Jeong, H.J.; Jeong, S.Y.; Lee, G.W. Highly concentrated and conductive reduced graphene oxide nanosheets by monovalent cation $-\pi$ interaction: Toward printed electronics. Adv. Funct. Mater. 2012, 22, 3307-3314.

84. Hou, S.; Su, S.; Kasner, M.L.; Shah, P.; Patel, K.; Madarang, C.J. Formation of highly stable dispersions of silane-functionalized reduced graphene oxide. Chem. Phys. 2010, 501, 68-74.

85. Park, J.S.; Na, H.K.; Min, D.H.; Kim, D.E. Desorption of single-stranded nucleic acids from graphene oxide by disruption of hydrogen bonding. Analyst 2013, 138, 1745-1749.

86. Wang, G.; Shen, X.; Wang, B.; Yao, J.; Park, J. Synthesis and characterisation of hydrophilic and organophilic graphene nanosheets. Carbon 2009, 47, 1359-1364.

87. Thomas, H.R.; Marsden, A.J.; Walker, M.; Wilson, N.R.; Rourke, J.P. Sulfur-Functionalized Graphene Oxide by Epoxide Ring-Opening. Angew. Chem. 2014, 53, 7613-7618.

88. Pham, T.A.; Choi, B.C.; Jeong, Y.T. Facile covalent immobilization of cadmium sulfide quantum dots on graphene oxide nanosheets: Preparation, characterization, and optical properties. Nanotechnology 2010, 21, 465603. [PubMed]

89. Choudhary, S.; Mungse, H.P.; Khatri, O.P. Dispersion of alkylated graphene in organic solvents and its potential for lubrication applications. J. Mater. Chem. 2012, 22, 21032-21039.

90. Di Crescenzo, A.; Di Profio, P.; Siani, G.; Zappacosta, R.; Fontana, A. Optimizing the interactions of surfactants with graphitic surfaces and clathrate hydrates. Langmuir 2016, 32, 6559-6570.

91. Hsieh, A.G.; Punckt, C.; Korkut, S.; Aksay, I.A. Adsorption of sodium dodecyl sulfate on functionalized graphene measured by conductometric titration. J. Phys. Chem. B 2013, 117, 7950-7958.

92. Achari, A.; Datta, K.K.R.; De, M.; Dravid, V.P.; Eswaramoorthy, M. Amphiphilic aminoclay-RGO hybrids: A simple strategy to disperse a high concentration of RGO in water. Nanoscale 2013, 5, 5316-5320.

93. Ye, M.; Cai, T.; Shang, W.; Zhao, L.; Zhang, Y.; Liu, D.; Liu, S. Friction-induced transfer of carbon quantum dots on the interface: Microscopic and spectroscopic studies on the role of inorganic-organic hybrid nanoparticles as multifunctional additive for enhanced lubrication. Tribol. Int. 2018, 127, 557-567. 